\title{
Sobre la trayectoria política, cultural e intelectual en los años sesenta y setenta de un cientista de la educación. Entrevista a Juan Carlos Tedesco
}

\section{Sebastián Gómez}

\begin{abstract}
Resumen
El artículo contribuye a la reconstrucción del itinerario del cientista de la educación Juan Carlos Tedesco (1944-2017) en los convulsionados años sesenta y tempranos setenta. Como otros intelectuales de la época, su trayectoria lejos de cristalizarse en una institución, estuvo signada por el pasaje en diversas formaciones: partidos políticos, universidades, institutos internacionales en las que atravesó sucesivas polémicas y fracturas como así también entabló vínculos entrañables. En algunos casos, en animosidad y en otras en articulación con estas instituciones, las juveniles intervenciones intelectuales de Tedesco permanecieron marcadas por la audacia al publicar su influyente libro Educación y Sociedad en la Argentina, 1880-1900 (1970) o dirigir la Revista de Ciencias de Educación (1970-1975) con apenas 26 años y, al mismo tiempo, la pretensión de vertebrar una crítica singular en el espacio pedagógico. En este último sentido, Tedesco se movió entre los pliegues del estudio científico del sistema educativo y la voluntad transformadora. Presumiblemente influido por sus experiencias infantojuveniles en el modesto barrio de Lomas del Mirador (Provincia de Buenos Aires), buscó no solo impugnar las dinámicas de las instituciones educativas, sino también iluminar las potencialidades que la escuela y la universidad pública contenían para los sectores populares.
\end{abstract}

On the political, cultural and intellectual trajectory in the sixties and seventies of an education scientist. Interview with Juan Carlos Tedesco

\begin{abstract}
This article aims to make a contribution regarding the reconstruction of educational scientist Juan Carlos Tedesco (1944-2017) itinerary in the convulsive 60s and early
\end{abstract}

Palabras-claves:

Juan Carlos Tedesco, crítica educativa, compromiso político.
Keywords

Juan Carlos Tedesco, educational critic, political compromise. 
1. Juan Carlos Tedesco, educational critic, political compromise.

2. Luis Osvaldo Tedesco publicó en 2. L6 Lomas del Mirador. Diccionario temático de voces. De manera literaria recrea escenas de aquellos años.

3. Los comicios fueron realizados el 5 de febrero de 1961 para elegir un diputado y un senador en la Capital Federal. El candidato del Partido Socialista Argentino, Alfredo Palacios que durante la campaña predicó una encendida defensa de la Cuba revolucionaria y un discurso antiimperialista, triunfó con el $21,63 \%$ de los votos (seguido muy de cerca por el candidato de la Unión Cívica Radical del Pueblo que alcanzó el $21,13 \%$ ) (Tortti y Blanco, 2000). Luis 21,13\%) (Tortti y Blanco, 2000). Luis
Tedesco (padre), luego de adherir al gobierno peronista, hacia fines de los cincuenta comenzó a simpatizar con el Partido Socialista. Aunque sin militancia política como sus hijos, se ofreció como Fiscal por elPS se ofreció como Fiscal por el PS en esas elecciones. Papel que también Juan Carlos no reunía la edad suficiente para actuar en esa condición, el PS lo designó Fiscal General: recorría las mesas recolectando los punteos (Luis Osvaldo Tedesco, comunicación personal, 20 de septiembre de 2017).

4. Hacia principios de los sesenta al interior del Partido Socialista Argentino convivían dos corrientes: moderados e izquierdistas. Éstos últimos, conmovidos por la experiencia de la Revolución por la experiencia de la Revolución
cubana (1959), su creciente enfrentaCubana (1959), su creciente enfrenta-
miento al imperialismo y la asunción de la condición socialista (1961) bregaban por la afinidad del partido con el

“fidelismo". Las tensiones y diferencias entre ambas tendencias encontraron un punto de quiebre durante 1961. La corriente izquierdista había ganado corriente izquierdista habia ganado
influencia y posiciones dentro del partido, ante lo cual la otra ala reaccionó intempestivamente. La Secretaría

Muñiz, expresión del ala moderada, no acató los resultados de las elecciones internas para la conformación del Comité Nacional que favorecieron a la normas partidarias, desconocieron los resultados electorales, se apropiaron por la fuerza de los locales e impidieron asumir a los miembros recientemente electos mientras dejaban que se vencieran los mandatos del viejo Comité. cieran los mandatos del viejo Comité. Cuando esto ocurrió, declararon que
el partido se encontraba en situación de "acefalía", designaron un Comité "provisorio" y expulsaron a las figuras más prominente del ala izquierdista, entre ellos a Davi también desplazaron de la dirección también desplazaron de la dirección del periódico partidario La Vanguardia). Los expulsados, con amplia influencia en sectores juveniles y universitarios, se ampararon en el hecho de ser la "mayoría legítima”, reorganizaron la Mesa Ejecutiva del Comité Nacional con Tieffenberg como Secretario General, y rebautizaron la publicación partidaria con el título La Vanguardia "roja". En los hechos, comenzaron a funcionar dos partidos en uno. Al poco tiempo, el ala moderada pasará a denominarse PSA Casa del Pueblo y el ala izquierdista, qusa del Pr que por entonces se llamaba Secretaría Tieffenberg, se convertirá en PSA de Vanguardia (Tortti, 2009). El nivel que alcanzó el enfrentamiento entre estas fracciones del Partido (por ejemplo, intentos por retener o recuperar, intentos por retener o recuperar,

los locales partidarios) provocó el los locales partidarios) provoco el
alejamiento de muchos afiliados. 70s decades. Like other intellectuals of his time, his career was not crystallized in a single institution: marked by his participation in several formations: political parties, universities, international institutes in which he went through successive polemics and disputes as well as endearing relations. Some of those cases with animosity and others aiming towards articulation with those institutions, Tedesco's intellectual youth interventions remained marked by his audacity to publish the influential book Educación $y$ Sociedad en Argentina (1880-1900) (1970) or by being Director of the Revista de Ciencias de la Educación (1970-1975) at 26 years of age and, at the same time with the intention to structure a singular criticism in the pedagogical field. On this issue, Tedesco walks between the scientific study of the educational system and his transformative will. Presumably influenced by his childhood and youth experiences in the Lomas del Mirador neighborhood (Buenos Aires), he sought not only to challenge the dynamics of educational institutions but also to illuminate the potentialities schools and public universities hold for popular sectors.

El 8 de abril de 2015, se entrevistó a Juan Carlos Tedesco (1944-2017) en el Instituto de Altos Estudios Sociales (IDAES) de la Universidad Nacional de San Martín (UNSAM), ubicado en la calle Paraná 145, Ciudad de Buenos Aires. La conversación tuvo lugar en la oficina desde donde Tedesco coordinaba el Programa de Mejora de la Enseñanza y el Doctorado en Educación de la UNSAM. En el marco de la tesis doctoral en Educación, La recepción y usos de Antonio Gramsci en el nacionalismo popular y la nueva izquierda pedagógica (1959-1976), Facultad de Filosofía y Letras, Universidad de Buenos Aires (UBA), el propósito de la entrevista residía en reconstruir su trayectoria política e intelectual en los años sesenta/setenta como así también su pionero empleo del comunista italiano en una pieza clásica de la historia educativa vernácula: Educación y sociedad en la Argentina, 1880-1900 (1970).

En su itinerario por los convulsionados años sesenta-setenta, resulta particularmente visible como se entrecruzan esferas inseparables para Tedesco: política, cultura y educación. La entrevista recorre diferentes contornos de su experiencia vital por aquellos años: la juventud en Lomas del Mirador; sus estudios en la Escuela Normal Superior de San Justo y las influencias y avatares del ambiente intelectual de la Facultad de Filosofía y Letras, UBA, donde se graduó como licenciado en Ciencias de la Educación en 1968; las incursiones, polémicas y distancias políticas con el Partido Socialista y Política Obrera; los vínculos con destacadas personalidades del ámbito cultural y educativo tales como Gregorio Weinberg y Juan Ricardo Nervi; la dirección ininterrumpida de la Revista de Ciencias de la Educación (1970-1975); el refugio en organismos internacionales ante la creciente persecución. A su vez, a través de notas al pie de página se pretende contextualizar y enmarcar algunos de los pasajes de la entrevista para facilitar su lectura. En esta línea se incorporan apreciaciones de su hermano mayor, Luis Osvaldo Tedesco que fue entrevistado en septiembre del corriente año. En la dedicatoria de uno de sus últimos libros, Juan Carlos Tedesco (2005) dejó entrever el entrañable y formativo vínculo con su hermano, anidado en las calles de Lomas del Mirador: "A Luis, mi maestro, desde pendejo".

E: -Por donde quería comenzar la entrevista es por tu itinerario político en la década del sesenta. Tengo entendido que habías participado del Partido Socialista, en sus tendencias izquierdistas, y después también en Política Obrera, lo que hoy sería Partido Obrero. ¿Cómo fue esa trayectoria por esos años, cómo recordás esa experiencia?

T: -Desde muy chico y siguiendo en ese momento un poco los pasos... yo tengo un hermano mayor [Luis Osvaldo Tedesco], casi 3 años mayor que yo... Cuando él tenía 
16, 17, yo tendría 14, 15 años. ${ }^{1}$ Recién estaba en el secundario. Él ingresó en el Partido Socialista... y bueno, no había gran reflexión, más que cierta consideración de valores, que eran claramente de izquierda, no comunista, es decir, no stalinista. Ese era un poco el eje con el cual el comunismo, el Partido Comunista argentino de esa época era percibido por los que no estábamos ahí: un partido stalinista, duro, autoritario, muy sectario en varios aspectos. En cambio, el socialismo tenía más flexibilidad y posibilidades de participación más democrática. Yo vivía en Lomas del Mirador en esa época. ${ }^{2}$ Entonces ingresamos en el centro socialista de Liniers. Un grupo humano formidable de gente. Yo era un pibe. Había un grupo de gente que me parecían muy divertidos y, además, militantes. Con mucho entusiasmo el día que ganó Alfredo Palacios la elección en la ciudad de Buenos Aires hicimos una fiesta descomunal. ${ }^{3} \mathrm{El}$ Partido Socialista, como todo el mundo sabe, tiene una vocación por la división muy fuerte, y va dividiéndose de a poco. Y yo seguí ese proceso, siempre quedándome del lado más de izquierda del grupo. Estaba en la universidad... un día, me acuerdo como anécdota muy simpática, viene el que era algo así como el presidente del comité central de la juventud socialista y me dijo que pensaban en mí para formar parte de ese comité. Yo dije: “¿Cómo? ¿Qué quiere decir, que arriba mío ya no va a haber nadie y abajo tampoco?" (risas). Porque abajo yo sabía lo que había. Yo era el que salía a pintar la pared, a pegar los carteles... somos nosotros... bueno, se reía; pero efectivamente, éramos dos, tres, cuatro. Me acuerdo cuando pintábamos esas cosas que no entendía nadie. Recuerdo ahora y me río: "PART SOC SEC EF" que quería decir "Partido Socialista Secretaría Tieffenberg" (risas). La persona que se levantaba a la mañana y leía, se preguntaba "quiénes eran estos locos”, “¿quiénes son?” Bueno, éramos nosotros. Así que ahí dejé, dejé el socialismo. ${ }^{4}$ Ya estaba en la universidad, y en ese momento comenzó a surgir Política Obrera, ${ }^{5}$ con su adhesión al trotskismo. Comencé a ver qué era eso, a leer a Trotsky, y encontraba cierta afinidad, entusiasmo. Primero, por su combate al stalinismo y después el pensamiento del trotskismo es un pensamiento muy creativo, muy fresco, de analizar la realidad a pesar de lo que era... También, había un perfil muy sectario, muy duro en términos organizativos. Era un grupo muy joven, [Jorge] Altamira en esa época tenía mi edad también, así que éramos todos muy buenos muchachos, estudiantes universitarios. La decisión de ruptura fue cuando el PO decidió proletarizarse. ${ }^{6} \mathrm{Y}$ yo venía de una familia muy pobre. Mi padre [Luis Tedesco] era albañil... ${ }^{7}$ Esto de que haya que proletarizarse... casi como curso de vida, dejar la universidad, meterme en una fábrica... Discutimos mucho todo ese tema, a mí no me cerraba, ni en lo personal. Por ahí uno justificaba teóricamente una decisión que era una decisión de vida. Y yo no me veía volviendo a tener una vida de obrero de fábrica. Ya estaba en la universidad, tenía ambiciones intelectuales, quería estudiar. Así que ahí también entonces me alejé del PO, quedé fuera de la vida política en términos de organizaciones políticas. Y comenzó una suerte de militancia por la educación. En ese momento estaba casi terminando la carrera, vino el golpe de 1966. A mí el golpe de 1966 me ayudó a definir, a terminar la carrera de educación, porque estaba a punto de cambiar...

E: - ¿A cuál te ibas a cambiar?

T: -A Filosofía, ese ambiente en la Facultad, donde había materias optativas. Había hecho Lógica con [Gregorio] Klimovsky, y me entusiasmó muchísimo; hice después Filosofía de la Ciencia con Klimovsky, y estaba a punto de cambiarme de carrera. Viene el golpe, renuncian todos... Me quedaban como 4 o 5 materias para terminar. Digo "las termino y me voy". Y así fue, terminé, di libres varias materias que me quedaban y me alejé de la universidad, del ambiente.

E: $-\dot{¿} Y$ ahí tuviste algún vínculo con el Instituto Torcuato Di Tella, con Gilda Romero Brest?
5. Política Obrera nació en marzo de 1964 y, en un principio, su inserción era fundamentalmente universitaria.

6. Política Obrera desplegó a mediados de los sesenta un importante trabajo sindical. En abril de 1967 . desarrolló las "Tesis sobre proletarización” y luego impulsó la Tendencia Estudiantil Revolucionaria Socialista (TERS) que pretendía suministrar los cuadros para la proletarización. La organización controló que todos sus miembros universitarios ingresen a trabajar en fábricas (Coggiola, 2006).

7. Juan Carlos y Luis Osvaldo Tedesco ayudaron a su padre, los sábados y domingos, en la construcción del hogar en un terreno comprado de Lomas del Mirador donde vivieron. Una obra que demandó varios años y también contó con la colaboración de los tíos (Onofrio y Nicolás) de Juan Carlos y Luis Osvaldo que estaban enrolados en el gremio de la construcción. Por su parte, Luis Tedesco tenía múltiples oficios. Estudiante del colegio industrial, su habilidad en el manejo de herramientas era vasta, aunque su trabajo más estable fue como almacenero. También en el almacén colaboraron asiduamente Juan Carlos y Luis Osvaldo Tedesco (Luis Osvaldo Tedesco, comunicación personal, 20 de septiembre de 2017). 8. En la casa de Lomas del Mirador se desarrollaron encuentros festivos con miembros del PS hacia fines de los años cincuenta y principios de los sesenta (Luis Osvaldo Tedesco, comunicación personal, 20 de septiembre de 2017). 
8. Con la intervención universitaria de 1966 fueron desplazados docentes del Departamento de Ciencias de la Educación de la Universidad de Buenos Aires (UBA). Algunos prosiguieron su inserción en el Centro de Investigaciones en Ciencias de la Educación del Instituto Torcuato Di Tella. Quien comandaba el Centro era Gilda Romero Brest, directora del Departamento Ciencias de la Educación de la UBA entre 1961 y 1966.

9. Creado en Ginebra en el año del Congress for Cultural Freedom Congreso por la Libertad de la Cultura (CLC)- que se fundó en Berlín a mediados de 1950 y tuvo sede en París. En el marco de la segunda posguerra, el propósito central del CLC era compensar, dentro de los conflictivos compensar, dentro de los conflictivos
enfrentamientos político-ideológicos de la Guerra Fría, las intervenciones del bloque soviético. Funcionó esencialmente a través de la promoción de eventos culturales (encuentros, conferencias, conciertos, exposiciones, galerías y bienales de arte), publicación de libros y revistas y, sobre todo, tejiendo vínculos internacionales entre la intelectualidad y la política. El CLC aglomeró a una resistencia política y activismo intelectual en defensa de la libertad del pensamiento por oposición a la censura y el totalitarismo soviético. El Congreso que llegó a contar con sedes de carácter permanente en más de treinta y cinco países y en los cinco continentes, incursionó en América Latina en 1953 a través de su revista órgano: Cuadernos (editada y dirigida organo: Cuadernos (editada y dirigida 1953 y 1965), versión española de su homónima francesa. Pero su inserción en la región aumentó cualitativamente con la creación del ILARI. Los institutos de la CLC (diseminados en cuatros áreas geográficas: Europa del Este, Europa mediterránea, Sudeste Asiático

y América Latina) se situaban a medio camino entre la instancia científica y los que hoy se denominaría think thank, puesto que su objetivo residía en recoger y analizar la información necesaria para presentarla a las instancias políticas pertinentes (gobiernos, organismos de cooperación internacionales, fundaciones filantrópicas, etcétera) junto con los datos y preconizaciones que pudieran ayudar a resolver los promas de los paises en vías de desarrollo (Ruiz Galbete, 2013).

10. Su verdadero nombre era Charles Cortvrint. Nacido en 1914 en Bruselas, Cortvrint. Nacido en 1914 en Bruselas,
se le conocerá también bajo los seudónimos de Charles Ridel, Damashki o Santiago Parane en distintas etapas de su vida. Su existencia como Luis Mercier Vega empezó en Santiago de Chile el 1 de octubre de 1940, fecha de expedición de su documento de identidad chileno. Se trataba de un periodista anarquista belga exiliado después

de la guerra civil española que residió en Chile durante la Segunda Guerra

Mundial pero también en Argentina (Jannello, 2013). Como parte de las acciones del CLC, Vega se hizo cargo de la dirección del ILARI en 1966 que tenía sede en Ginebra y las oficinas adminis-

trativas en París, pero sus actividades esenciales se llevaban a cabo en gran parte de las principales ciudades de parte de las principales ciudades de
América Latina, especialmente en Chile. Jóvenes camadas se hicieron cargo de las sedes del ILARI en la región. Tal fue el caso de Tedesco que asumió la dirección de la sección de Ciencias Sociales del Instituto en Buenos Aires desde 1968 hasta su cierre en 1973.
T: -No, no, Gilda y su grupo se fueron al Di Tella, ${ }^{8}$ pero no..., después ahí tuvimos contacto con un instituto: el Instituto Latinoamericano de Relaciones Internacionales (ILARI), que editaba una revista, Aportes. ${ }^{9}$ En su dirección estaba Luis Mercier Vega, que era un anarquista francés, medio raro... ${ }^{10}$

\section{E: -Que te apoyó en tu libro [Educación y sociedad en la Argentina (1880-1900)]...}

T: -Claro, claro, y la revista [Revista de Ciencias de la Educación, 1970-1975]. En ese sentido me apoyaron. ${ }^{11}$ Era un grupo más independiente. Gilda nunca vio con buenos ojos la revista, porque no entendía "cómo podía ser que se hiciera algo sin ella" y "cómo podíamos sacar una revista sin que ella fuera.... Y yo dije: "bueno, la revista somos nosotros, somos tu producto", salimos... La revista salió por su lado y el grupo del Di Tella sacó algunas investigaciones, en ese momento interesantes. Pero no teníamos contacto ni institucional y ni siquiera personal. Éramos como dos mundos distintos.

E: -Además de Klimovsky, en alguna ocasión mencionaste la influencia de Gino Germani en esa época, y de alguna manera tu libro [Educación y Sociedad en Argentina, 1880-1900] tiene algunas huellas de...

T: -Y bueno sí, vivíamos todos en una facultad donde... imagínate, la carrera de Filosofía con todo esto, en Sociología Gino Germani, Jorge Graciarena, Miguel Murmis. Había un ambiente intelectual de una gran riqueza. En ese momento... yo personalmente, y bueno un poco alguna gente que estaba conmigo, estábamos en una situación bastante... [silencio] no digo incómoda, pero sí marginal respecto a los grupos dominantes. Germani y todo el sector del rector, de Risieri Frondizi [se desempeñó como rector entre 1957-1962], eran acusados de cientificismo por toda esta corriente más popular, populista, que tenía contenido social, pero... nosotros decíamos "esto desde el punto de vista de la calidad académica, es cero". La verdad que el rigor, la seriedad en los análisis, la introducción de la metodología científica en el conjunto de las Ciencias Sociales, incluso la educación, venia de toda esta gente, y para nosotros era muy valioso eso, muy valioso. No lo podemos perder en función de un discurso demagógico, populista... Me acuerdo en esa época [José] Nun denunciado como agente de la CIA porque estaba haciendo un proyecto sobre marginalidad... porque recibía fondos de la Fundación Ford era un agente de la CIA. ${ }^{12}$ Un delirio completo. Y bueno, en ese mundo y en el contexto de esos grupos había que moverse, y así nació la revista [Revista de Ciencias de la Educación]. La revista nació con ese enfoque, diciendo "nosotros queremos hacer algo donde este pluralismo sea un valor", respetado, y que podamos discutir, manteniendo sí esta idea de que no podíamos renunciar a la excelencia académica. No había contradicción en tener excelencia académica y compromiso social; al contrario, compromiso social sin excelencia académica era demagogia, y excelencia sin compromiso era la tecnocracia y era definitivamente la derecha. Pero sí, el libro de Germani Estructura social de la Argentina provocó un shock, porque era un análisis. Por fin, uno decía "bueno, tenés datos, tenés que discutir, no son opiniones". ${ }^{3}$

E: -En la hipótesis de tu libro Educación y sociedad, citás a Antonio Gramsci. Es un pasaje tan puntual como decisivo. Te quería preguntar por qué lo citaste, cómo accediste a él...

T: -Y bueno, porque en ese mundo, y en ese contexto de discusión política, ideológica, el enfoque de Gramsci me permitía salir del marxismo vulgar, de las interpretaciones del desarrollo la educación argentina como una variable dependiente exclusivamente de los datos y el enfoque del tipo de desarrollo económico, que, curiosamente era, sin tener absolutamente nada de marxista, el enfoque de [Gustavo] Cirigliano y de otras personas que hacían una extrapolación lineal entre modelo agroexportador y sistema educativo. Y cuando veías el análisis, el pensamiento político educativo de Sarmiento, 
la gente de la generación del ochenta, las decisiones que se tomaron... esa explicación no era fértil. Para ese modelo económico no hacía falta tener una educación primaria obligatoria, laica, un Estado activo en la educación. Y la hipótesis iba por el lado de lo político, es decir, introducir una variable política como una variable fundamental. En la búsqueda de ciertos marcos teóricos que contribuyan a colocar esta idea de lo político en un contexto que no fuera una cuestión muy parcial, el aporte de Gramsci era muy fértil. Permitía seguir cierta tradición marxista de análisis y no caer en el marxismo vulgar, y tampoco ir a una explicación funcionalista o de otro tipo. Es decir, yo no soy, no fui nunca un estudioso de Gramsci, pero leí sus obras, y me inspiró...

E: -Observé una suerte de combinación entre Gino Germani en esa obra, y Gramsci para pensar el surgimiento de nuestro sistema educativo. ¿Cómo se explica esa articulación?

T: -Yo siempre me sentí, y me hicieron sentir los demás, como muy heterodoxo. Yo no le tengo miedo a nada, porque hay gente... como que citar a uno o a otro pareciera una herejía ¿por qué no? ¿Cuál es el límite? ¿Quién me va a poner a mí un límite...? Si cito algún concepto de Germani ya soy un funcionalista parsoniano y si cito Gramsci... No... la idea... y eso, eso lo aprendí de Klimovsky, es la idea de la fertilidad.

E: -Sí, de formular una hipótesis fértil.

T: -Claro, y que vos promuevas una hipótesis y la hipótesis es válida si te explica una gran cantidad de problemas, cuanto más expliques más fértil y más valida, punto; si eso es Gramsci, Germani o quien sea, no importa, lo importante es el contenido de la hipótesis. Y bueno, además, en ese libro yo tenía 25 años cuando lo escribí, así que era un... pibe (risas)...

E: -Y lo que me interesaba preguntarte era cómo accediste a los escritos de Gramsci. Gregorio Weinberg te hizo un puente, fue una lectura tuya personal, lo leíste en la universidad...

T: -Estaba ahí. O sea, alguien inquieto no podía no leer a Gramsci, como no podía no leer a Marx, no leer a Trotsky. La literatura de la época era toda una literatura política. Tenías Pasado y Presente como revista, como colección de libros..$^{14}$ Estábamos rodeados de una literatura, toda de origen marxista. Althusser vino después, pero bueno... en la universidad, en esa época, no leer y no estar al tanto de estos autores era ser un marginal completo. Así que no te puedo decir de quién. Cualquiera con alguna inquietud llegaba, y además los tenías ahí a los libros, no hacía falta hacer un gran esfuerzo para conseguirlos.

E: - Terminaste la carrera en 1968. ¿Cómo continuó tu trayectoria formativa? Te pregunto porque está la paradoja de que estudiaste Ciencias de la Educación en la Facultad de Filosofía y Letras de la Universidad de Buenos Aires, pero nunca regresaste, aun cuando finalizó la dictadura en 1973.

T: -Yo al mismo tiempo trabajaba en una escuela secundaria. Era profesor y vicedirector de un secundario, con Nervi, Juan Ricardo Nervi, que fue mi profesor en la escuela Normal, ${ }^{15}$ y después en la Facultad. Entonces siempre tuve un pie en el sistema educativo real. ${ }^{16}$ Hasta que sí, en 1973 cuando sube el peronismo, es notable... A la universidad de Buenos Aires no volví. Fui discriminado por marxista. La dictadura me discriminaba por marxista y el gobierno nacional y popular también me discriminaba por marxista. Después me pidieron perdón, muchos años después, pero en ese momento no. Y ahí me fui, primero al Comahue, porque se empezaban a crear estas nuevas universidades ${ }^{17}{ }^{17}$ el Comahue estaba [Roberto] Domecq de rector, se había armado un lindo grupo, estaba [Juan Carlos] Portantiero. En educación también se armó un grupo lindo. Viví un año
11. El ILARI financió los primeros cuatro números de la revista (entre abril de 1970 y marzo de 1971).

12. En 1966 el Instituto Latinoamericano de Planificación Económica y Social (ILPES) de la Comisión Económica para América Latina y el Caribe (Cepal) junto con el Centro de Desarrollo Social de América Latina (DESAL) que tenía su sede en Chile, impulsaron el proyecto sobre Marginalidad Social en América. José Nun asumió la dirección de investigación del proyecto. El financiamiento provenía principalmente de capitales alemanes, pero también de agencias de financiamiento europeo y de agencias norteamericanas, entre las que se encontraba la Fundación Ford.

13. Estructura Social de la Argentina (1955) constituyó la primera pesquisa local basada en los datos aportados por los primeros cuatro censos generales de población realizados entre 1869 y 1947.
14. Estructura Social de la Argentina (1955) constituyó la primera pesquisa local basada en los datos aportados por los primeros cuatro censos generales de población realizados entre 1869 y 1947.

15. En la Escuela Normal Superior Mixta de San Justo, Nervi fue profesor de Juan Carlos Tedesco en la materia Pedagogía en cuarto y quinto año. Según Luis Osvaldo Tedesco, Nervi junto con Gregorio Weinberg constituyeron dos figuras decisivas en la trayectoria intelectual de su hermano (Luis Osvaldo Tedesco, comunicación personal, 20 de septiembre de 2017).

16. En la Escuela Normal Superior Mixta de San Justo, Nervi fue profesor de Juan Carlos Tedesco en la materia Pedagogía en cuarto y quinto año. Según Luis Osvaldo Tedesco, Nervi junto con Gregorio Weinberg constituyeron dos figuras decisivas en la trayectoria intelectual de su hermano (Luis Osvaldo Tedesco, comunicación personal, 20 de septiembre de 2017).

17. En calidad de Profesor Titular e Investigador en Historia de la Educación Argentina, Facultad de Ciencias de la Educación de la Universidad Nacional del Comahue entre 1973 y 1974. 
18. En calidad de Profesor Titular e Investigador en Historia de la Educación Argentina, Facultad de Ciencias de la Educación de la Universidad Nacional del Comahue entre 1973 y 1974.

19. Falleció en 1974 (Luis Osvaldo Tedesco, comunicación personal, 20 de septiembre de 2017).
20. El ILARI y el propio Tedesco mantuvieron fluidos vínculos con esta institución desde fines de los sesenta. Tedesco dirigió la Maestría en Ciencias Sociales con orientación en Educación de

FLACSO Argentina entre 1981 y 1982 y estuvo a cargo del curso sobre Políticas Educativas. Además, fue el primer director del área Educación de la FLACSO Argentina.

21. El libro llevó por título El proyecto educativo autoritario: Argentina 19761982. Fue publicado en noviembre de 1982 por FLACSO Argentina y resultó una pionera contribución en el análisis crítico de las consecuencias educativas de la última dictadura cívico-militar. Luis Osvaldo Tedesco participó en el trabajo de edición. en el Comahue hasta que ahí los procesos ya se empezaron a acelerar. En 1974 vino la intervención... tuvimos que salir corriendo. Y hubo un paso intermedio por La Pampa, por la Universidad Nacional de La Pampa, que había un rector, [Alfredo] Domínguez, que nos captó a varios de educación, a Juan Carlos Geneyro, Alfredo Furlán, Susana Rodríguez, Justa Ezpeleta, que iba y venía de Córdoba a La Pampa. También eso duró un año. ${ }^{18}$ Hubo que salir corriendo. Y ahí bueno, yo volví, volví a Buenos Aires y en ese momento, una circunstancia personal compleja porque... Justa, por ejemplo, Alfredo Furlan, Geneyro, todos empezaron a migrar. Se iban a México, pero yo tenía mi padre internado, con un cáncer. ${ }^{19}$ No me podía ir. Y, al mismo tiempo, apareció una posibilidad, se había instalado acá en Buenos Aires, un año antes, la oficina de la Comisión Económica para América Latina y el Caribe (Cepal). La Cepal de Santiago de Chile a partir del golpe de Pinochet [11 de septiembre de 1973] empezó a abrir oficinas en los países. Entonces inauguraron la oficina acá en Buenos Aires, en México, que todavía existen. En Buenos Aires, existió un proyecto de educación, comandado por Germán Rama. Un proyecto llamado Desarrollo y Educación en América Latina con sede en Buenos Aires, porque no lo podían tener en Santiago de Chile. Él se vino para acá [en 1974]. Se instalaron antes del golpe. Yo lo conocía a él por el libro. También [Jorge] Gracierena y Aldo Solari, vinculados a la Cepal, habían considerado el libro. Me dijeron: "mirá, tengo un puesto de asistente de investigación acá en el proyecto", ni siquiera de profesional. Y yo dije: "mirá, lo agarro", con tal de quedarme y además me daba una cierta cobertura al estar dentro de un organismo de Naciones Unidas. La fantasía era que te protegía un poco... Y así fue que empezó mi carrera en la Unesco.

\section{E: -Pero ¿cuándo te fuiste del país?}

T: -Me fui después, porque el proyecto duró hasta el año 1980, 1981. Ahí termina el proyecto y había una posibilidad de que yo siguiera en la Unesco en Caracas, en Venezuela, pero como son los trámites de estos arreglos internacionales, demoran, lentos. Bueno la cuestión es que el proyecto con Germán [Rama] terminó y no había salido lo de Venezuela. Entonces como ya a esa altura todo empezaba a ser un poquito más blando. Ahí se armó la Maestría en educación de Facultad Latinoamericana de Ciencias Sociales (FLACSO).$^{20}$ Hablé con Jorge Feldman, que era nuestro director. En esa condición, le dije: "bueno mirá..., dentro de la maestría en Ciencias Sociales, hay que proponer una especialidad en Educación”. Le interesó mucho, la armamos; nuevamente ahí tuvimos cierto roce con Gilda, porque para armarla llamamos a varios, de los viejos y de los jóvenes, y cuando Feldman la llama a Gilda para convocarla a una reunión, Gilda dice, -Pero ¿cómo no me pediste a mí que lo organice?, pero... -Escúchame... (risas)... este proyecto lo trajo Juan Carlos, no es que yo se lo pedí...

E: -Un poco eso que dijiste alguna vez, que Gilda no podía creer que ustedes saquen una revista...

T: -Claro, no podía creer que saquemos una revista, no podía creer que armemos una Maestría. Nos subestimaba totalmente. Largamos entonces la Maestría. Se sumó Cecilia [Braslavsky], estaba [Carlos] Borsotti, había un grupo lindo de gente. Empezamos. Ahí salió... el producto de ese periodo más importante fue el libro sobre el Proyecto Educativo Autoritario. ${ }^{21}$ Y como al año de estar ahí, finalmente la Unesco decidió..., en ese momento una decisión difícil, lo que pasa es que todavía nadie preveía que la dictadura iba a terminar. En la Unesco ya había varias personas que se habían movido mucho para conseguir que me dieran el puesto, porque no era fácil, porque normalmente el gobierno controlaba mucho los nombramientos. Para nombrar un argentino había que pasar a todas las autoridades del gobierno que estaban en la Unesco, al delegado permanente de Argentina ante la Unesco, que en ese sentido se portó muy bien, era Víctor Massud. También estaban Luis Nassif, Ricardo Nassif. Bueno toda esa gente que se había movido mucho me dijo: "ahora no nos dejes en banda, habíamos encontrado 
ese laburo para que te nombren, no digas que no". Estaba Enrique Oteiza, porque el puesto era en el Centro Regional de Educación Superior en América Latina y el Caribe (CRESALC) en Venezuela. El director del CRESALC era Oteiza en ese momento. Bueno, y acá estaba Cecilia que ya mostraba una polenta bárbara para hacerse cargo de la maestría. Yo por supuesto no me desvinculaba del todo, no es que me iba a otro planeta, entonces me fui a Caracas.

E: -Entendí entonces un poco mejor el ocaso de 1976 y como continuaste trabajando. Lo que me interesaba retomar era la experiencia de la revista. En principio, una pregunta introductoria ¿por qué el nombre?, ¿por qué Revista de Ciencias de la Educación?

T: -Y porque eso era. En ese momento el campo disciplinario de las Ciencias de la Educación era una novedad. No mucho tiempo atrás habría sido Pedagogía. Ciencias de la Educación era esta idea de introducir a la educación dentro de un enfoque científico. Superaba la idea de lo pedagógico, superaba la idea de lo filosófico. Además, yo creo que la mía debe haber sido la segunda generación o camada de estudiantes de Ciencias de la Educación, la primera fue la de Fernández Lamarra.

E: -Sí, eso me interesaba porque era una cuestión bastante juvenil también.

T: Sí, sí, pero además como enfoque. Antes no existía la carrera de Ciencias de la Educación. Era Pedagogía, y Pedagogía espiritualista a través de [Juan] Mantovani y todo un enfoque antipositivista. ${ }^{22}$ Entonces, venía toda una tradición de los estudios de educación, muy basados en un enfoque no científico. Entonces dijimos, "aquí vamos a introducir ciencia". Por eso el nombre...

E: -También debía llamarle la atención a Gilda con ese nombre...

T: -Claro... se ofendió profundamente. Nos apropiábamos de un enfoque, que ella había sido la que había impulsado. Pero en vez de considerarlo como un triunfo de ella, lo consideraba como que estábamos usurpando. Todo lo contrario de profesores como Gregorio Weinberg que tenía una generosidad fabulosa. Cuando fui con el libro [Educación y sociedad, 1880-1900] tenía mucho miedo. Le dije: -Profesor, mire..., pero inmediatamente se entusiasmó, me dijo, -Yo te escribo el prólogo. -Era un hombre culto, una especie de humanista que leía todo. Además, era editor.

E: -Y la revista, por lo que tengo entendido, es impulsada por egresados de la UBA hasta el número 7 (abril de 1972).

T: -Originalmente sí fue un grupo de la UBA, pero poco a poco fuimos buscando gente en Córdoba, en La Plata, en Tucumán. Se integran Justa Ezpeleta, Julia Silber, Clotilde Yapur...

E: -Sí, había como un eje digamos... La Plata, Buenos Aires, Córdoba y Tucumán...

T: -Y sí, eran en ese momento las principales universidades y además las que tenían carreras de Ciencias de la Educación.

E: $-\dot{i}$ Y Roberto Gargiulo?

T: -Y no, Roberto estaba estudiando en Ciencias de la Educación, pero él venía del profesorado. No tenía un gran perfil académico.

E: $-i$ Él donde estudiaba?
22. En marzo de 1957 se crea la carrera de Ciencias de la Educación en la UBA en reemplazo de Pedagogía. 
23. En marzo de 1957 se crea la carrera de Ciencias de la Educación en la UBA en reemplazo de Pedagogía.

24. A través de una de sus editoriales: Axis.
T: -Yo creo que en el Profesorado del Joaquín V. González, no estoy seguro. El que venía del profesorado era Guillermo García. Pero lo que te quería decir es que la revista era una empresa absolutamente artesanal. Artesanal en el sentido de que no solo buscábamos los artículos. Había que ir a la imprenta, diagramarlo, con el tipógrafo, poner esto, sacarle tal color. Y una vez que salía la revista había que llevarla a los kioscos para que la vendan. La llevábamos nosotros. Había mucho trabajo material alrededor de la revista. En ese sentido existía espacio para distintas personas. Hacía falta gente que estuviera dispuesta a armar un sobre, poner una estampilla, mandar por correo o caminarse la Avenida Corrientes, ${ }^{23}$ los kioscos, las librerías y ver si vendiste, cobrarles. Era una empresa casera y funcionaba muy bien para sorpresa de todos nosotros. Fue creciendo la cantidad de suscriptores, de ejemplares que se vendían, al punto tal que ya en la última etapa, vino una oferta de la Biblioteca [Popular Constancio] Vigil, de Rosario, para editar la revista con ellos. ${ }^{24}$

E: -El último número doble [septiembre de 1975] se edita con ellos...

T: -Sí, y después se agudizó la persecución y ya no la pudimos sacar más. Pero ya habíamos pasado a una fase no artesanal. Ya no podíamos editarla como antes. El volumen de actividad requería alguien que se ocupara de la imprenta, de la distribución, de los cobros. Y bueno alcanzamos a sacar un número, y ahí se terminó. Nosotros teníamos la dirección y el depósito en la calle Cuba...

\section{E: -Cuba 1940.}

T: -Sí, que es donde funcionaba la escuela Mundo Nuevo. Un día me llama la directora de la escuela y me dice: "Mirá Juan Carlos, vino un tipo acá medio sospechoso, con la excusa de que se quería suscribir a la revista empezó a hacer preguntas, quiénes eran, dónde estaban”. Nos pareció muy raro. Y bueno, era una escuela, no podíamos poner en riesgo... así que ahí tuvimos que improvisar autos, amigos, y en eso la Cepal... el director de la Cepal acá en Buenos Aires en esa época era [Alfredo Eric] Calcagno, el padre del Senador [Eric Calcagno], Le expliqué, y sin duda me dice: “Tráelo acá, traé todo acá". La oficina estaba ahí en Paraguay al 1100. Y la verdad fue esa cosa de solidaridad que había en esa época. Gente que yo apenas conocía, otros que bueno, eran de la revista... Tuvimos que armar en horas, ir con autos, con lo que teníamos, vaciar todo el depósito y llevarlo; pero ahí ya habíamos decidido que no seguíamos. También la Biblioteca Vigil en Rosario empezó a ser perseguida.

E: -Y hay un momento -que es el número 7- donde hay dos grandes cambios. Por un lado, el nuevo apoyo institucional de Mundo Nuevo y, por otro, el ingreso de nuevas camadas o nuevos graduados de otras universidades. También aparece ahí como un punto donde se empieza a difundir de manera más fuerte todo lo que es la discusión marxista en educación: Illich, Freire, Althusser, Bourdieu. Te quería preguntar ¿cómo resultó introducir esta discusión en el ambiente de la época?

T: -Es que, te repito, esa era la discusión de la época, no entrar en esa discusión era estar al margen de lo que estaba pasando, si esa era la discusión.

E: -Pero parece como un punto de quiebre entre lo que se venía discutiendo hasta el número 6 [noviembre 1971], como una especie de salto...

T: -No... Cuando uno publica una revista publica lo que se produce, no publica lo que no se produce. Entonces se empezaba a producir, la gente empezaba a producir sobre estos temas, entonces, había ya condiciones de publicarlo. Hasta un poco antes todavía no había una madurez suficiente para esa discusión. Era una discusión que

empezaba, y tenías, por un lado, toda la corriente Freire, Illich, antiescuela. ${ }^{25}$ Después
25. El número 10 (octubre de 1973) de la revista se consagró al debate de esta corriente. El editorial de n. ${ }^{\circ} 10$ de la revista (octubre de 1973), presumiblemente escrita por Tedesco, entrecomillaba como "contestarias" a las teorías críticas de Ivan Ilich y Paulo Freire. 
empezamos a distinguir las posiciones de cada uno. Yo personalmente le tenía una profunda desconfianza a todo ese enfoque... Desconfianza desde el punto de vista teórico y político; la idea esta de que justo en el momento, en América Latina, que los sectores populares estaban teniendo acceso a la escuela, nosotros le venimos a decir que la escuela no sirve para nada. Hay un libro, del que era Ministro de Educación de Bolivia en ese periodo, cuando estaba el periodo de la revolución, Mariano Baptista Gumucio, que se llama Salvemos a Bolivia de la escuela, prologado por Ivan Illich ${ }^{26}$ iPero si los que no quieren que los bolivianos vayan a la escuela son la oligarquía boliviana! Bolivia ha estado desescolarizada toda la vida. O sea, percibir la escuela, al maestro como el enemigo era una corriente. Después empezaba a aparecer todos los enfoques de la teoría de la reproducción.

E: -En ese momento, ¿cómo se la denominaba a esa teoría? Porque la reproducción fue un mote posterior.

T: -Teoría de la reproducción. Además, el primer libro de [Pierre] Bourdieu y [JeanClaude] Passeron se llama así: La reproducción. ${ }^{27}$ Estaba todo dentro de este encuadre de pedagogía crítica. Y además con una particularidad, y es que los portadores de ese tipo de pensamiento llegaban al poder. Ahora la persona que pensaba que había que desescolarizar era el Ministro de Educación. ${ }^{28}$ Entonces eran teorías que salían del nimbo de la pura teoría y empezaban a aplicarse con consecuencias que no eran así banales. Ahora, en ese momento, ese era el debate que había. Fue muy incipiente. El golpe de 1976 y la dictadura clausuraron el debate que comenzó a correr por ciertos carriles más marginales. A veces, yo creo que hay como un exceso de reflexión sobre las cosas. Las cosas se hacían, no había mucha planificación. Y en cuanto a qué se publicaba o qué no se publicaba, dependía de lo que había para publicar, lo que se producía. Nosotros tratábamos siempre de privilegiar la producción local, tradujimos pocas cosas, pero a veces traducíamos, ${ }^{29}$ empezamos a publicar también cosas del resto de América Latina: textos de [Tomás] Vasconi (1973), por ejemplo. Uno de los exponentes de todo este enfoque marxista, crítico, antiescuela fue el trabajo de Vasconi que estaba en Chile. Era argentino, pero estaba en Chile. Lo mismo el pensamiento de Freire que empezaba a tomar cuerpo y con esa cosa muy atractiva, paradójicamente, para los que no eran de educación. Porque los que veníamos de educación no pensábamos que el maestro era el amo y el alumno el esclavo y que el proceso de aprendizaje era pura imposición ideológica. Sí, estábamos todos contra la didáctica autoritaria, todo estaba muy bien, pero equiparar el proceso de enseñanza aprendizaje con el proceso de explotación capitalista nos parecía un salto, una extrapolación... teóricamente incorrecta y políticamente muy peligrosa, porque entonces te colocabas con los maestros enfrente. $Y$ así fue, la reforma peruana [en marzo de 1972], por ejemplo, reformas antimaestros; y la verdad... tenés escuelas, tenés maestros, tenés contenidos. Pero bueno, ya te digo, en ese momento, el golpe militar abortó todo y a partir de ahí ya las discusiones más bien pasaron a otro nivel: contra el pensamiento autoritario de las dictaduras. El libro El proyecto educativo autoritario, en ese sentido fue también para mí, para el grupo, un libro importante. Pusimos en la agenda del debate los nuevos problemas. Discutir a Freire y compañía me parecía anacrónico.

E: -Ahora lo que me interesaba es que ustedes se trataban de desmarcar de Illich, de Freire, pero a su vez tomaban los aportes de Althusser o Bourdieu e intentaban incursionar en propuestas educativas. Esa combinación me llamaba la atención, ¿cómo trataban de resolverla desde una publicación?

T: -Y era lo que teníamos, porque recién con la vuelta a la democracia pudimos... se pudo. Actores, investigadores, gente que estaba en el mundo académico, de la educación, acceder a puestos de conducción. Pero hasta ahí lo único que tenías era la posibilidad de influir en el pensamiento, y que no te mataran. Fue recién con la democracia.
26. Se publicó en La Paz, Bolivia, en 1971 por la editorial Amigos del Libro.

27. La Reproducción: elementos para una teoría del sistema de enseñanza. Tedesco accedió a la edición en francés del libro, publicada en 1970 (Amar, 2016).

28. Por ejemplo, Mariano Baptista Gumucio se desempeñó como Ministro de Educación y Cultural entre 1969-1970 durante la administración boliviana de Alfredo Ovando Candia.

29. Por ejemplo, Mariano Baptista Gumucio se desempeñó como Ministro de Educación y Cultural entre 1969-1970 durante la administración boliviana de Alfredo Ovando Candia. 
30. El primer número de Los Libros apareció en julio de 1969 y el último, el n. ${ }^{\circ} 44$, en enero-febrero de 1976. Héctor "Toto" Schmucler dirigió la publicación hasta el n. 29 (marzoabril de 1973). A partir de entonces y motivado por una discusión políticoideológica, la dirección pasó a manos de Carlos Altamirano, Ricardo Piglia y Beatriz Sarlo. El n. ${ }^{\circ} 40$ (marzo-abril de 1975) explicitó otra crisis política en la publicación que implicó el distanciamiento de Ricardo Piglia.
Desde el peronismo de 1946 en adelante, la posibilidad de que personas de orientación política de izquierda, tuvieran acceso a manejar algunos dispositivos de poder era impensable. Entonces la idea de propuesta estaba un poco descartada, hasta la propia teoría te hacía descartar la idea de que pudiera postular propuesta de transformación. Eso recién empezó a ser posible con la democracia, con el congreso pedagógico. Ahí empezaron a aparecer ya con más legitimidad la idea de que era no solo posible, sino necesario hacer propuesta.

E: -Cuando revisaba la revista en paralelo leía la publicación Los libros [1969-1976]. Había mucha familiaridad, no solo porque ustedes escribían en una o en otra, sino también como proyecto ¿Cómo era el lazo entre esa revista?

T: -Eran más bien lazos..., en el sentido último, afinidad, cierto enfoque común y después ya eran vínculos personales, con [Carlos] Altamirano, con Beatriz Sarlo. ${ }^{30}$ Todos participábamos, además, de ese juego artesanal, de sacar la revista, de estar en el día a día, en algún punto era muy divertido (risas)... Era muy divertido porque vos lo veías desde el artículo escrito a máquina al producto final, y después venderlo en el quiosco. Era una actividad muy linda. Este país en ese momento, intelectualmente, era muy rico, se debatía mucho, se discutía, se leía mucho.

E: -Y después, ya para ir terminando, te quería preguntar, por la afiliación política de los miembros de la revista. En ese momento, entre tanta ebullición política ¿dónde te enmarcabas? ¿te acordás la afiliación política de alguno de los principales miembros de la publicación?

T: -Yo en ese momento estaba como una especie de independiente. Había dejado el trotskismo. No estaba puesto en ninguna organización. Había algunos miembros del Consejo que estaban más vinculados al peronismo, incluso al montonerismo. En general, salvo así dos o tres personas que estaban vinculados al peronismo, el resto éramos independientes, sin una afiliación política clara. No era fácil mantenerse en esa posición porque había una presión muy fuerte... pero quizás, justamente, los que estábamos en el núcleo duro de la revista, esa idea de la independencia, desde el punto de vista de los grupos políticos nos daba más libertad de opinión, de acción, dialogábamos con todo el mundo, con alguno nos peleábamos bastante. Cuando discutieron quién iba a dar la cátedra de Historia Educación Argentina en la UBA, la que en ese momento era la decana dijo: "No, no porque es marxista" y se la dieron a [José María] Castiñeira de Dios. Bueno, qué se le va a hacer...

E: -¿Cómo viviste vos o el núcleo de la revista la asunción de Cámpora, el FREJULI? ¿Tenían expectativas?

\section{T: -Sí, sí, claro.}

E: -Porque muchas veces se desmarca del peronismo la revista. De hecho, artículos de tu autoría en la revista $\operatorname{Los} \operatorname{Libros}^{31}$ y $\mathrm{FLACSO}^{32}$ a principios de los setenta dan cuenta de un análisis crítico del peronismo en su faceta educativa, pero la publicación también parece guardar expectativa en la asunción de Cámpora. ${ }^{33}$

T: -Sí, la veíamos obviamente muy bien. ${ }^{34}$ Pero también observábamos con mucha preocupación el tema de la lucha armada como mecanismo, veíamos con mucha preocupación la penetración en el pensamiento educativo de la gente que estaba en el montonerismo de Freire y todos esos enfoques. En cambio, veíamos con mucha simpatía, por ejemplo, el programa justicialista para la reforma educativa que impulsaba Rolando García. Recuerdo una discusión una vez en el Comahue con una de las personas que, políticamente, era la que más o menos comandaba todo el grupo peronista montonero, 
que discutía la presencia de Piaget en los contenidos de la carrera porque "Piaget trabajó con chicos de la burguesía en situación de laboratorio". Esa fue la respuesta. ¡Me pareció de un primitivismo! Pero eso pasaba. Se privilegiaba mucho más el discurso, la movilización y no el estudio científico. Ese era un poco nuestro valor; podemos ser socialmente comprometidos, pero con propuestas sólidas científicamente, porque estas otras que parecen muy comprometidas socialmente dejan a los estudiantes sin aprender. Porque esta es la verdad. Con estas propuestas los estudiantes no aprenden, y nuestro trabajo es que aprendan no que no aprendan. Aprender a leer y escribir, aprender matemáticas, aprender ciencia no es todo ideología, porque si fuera así estaríamos cediendo a la derecha todo el patrimonio cultural de la humanidad. Y te digo que ese debate sigue vigente.

E: -Sí, claro. ¿Qué difusión tuvo la revista?, ¿en sectores universitarios?, ¿sectores medios?

T: - La revista se difundía fundamentalmente entre los estudiantes de Ciencias de la Educación de las universidades. Un poco maestros, pero básicamente era bibliografía de las cátedras de las universidades. Esa era la fuente básica que permitía que la revista se vendiera y que fuera utilizada. El público eran los estudiantes, los profesores... que, además, a esa altura ya era un público masivo, porque si tomabas la cantidad de estudiantes de Ciencias de la Educación en las distintas universidades era una cantidad considerable. La revista editaba tres mil ejemplares.

E: - ¿Siempre editó tres mil?

T: -Tres mil, bueno, cuando la tomó la [Biblioteca Popular] Vigil sacó un poco más, pero siempre estuvimos ahí, en tres mil, cuatro mil ejemplares.

E: -Respecto al ILARI, ¿fue solamente financiera la ruptura o existió alguna otra razón?

T: -No, al principio... no tenían mucho que ver con esto. Me tenían simpatía, me dieron un apoyo financiero para empezar a sacarla. Pero la verdad que ya después del tercer, cuarto número, la revista empezó a autofinanciarse..$^{35}$ Tampoco ganábamos nada, o sea que se autofinanciaba la revista. Eso también nos dio mucha libertad, poder de iniciativa propia. Después teníamos mucha presencia con los canjes de avisos, que entonces...

E: -Que también publicaban ustedes en Los libros, por ejemplo.

T: -Claro... todo era canje, nadie ponía plata... "Yo te publico el aviso a vos, vos me publicás el aviso a mí". Ahora, eso daba mucha difusión, mucha vida, porque por ahí gente que no era de educación, se enteraba, veía algún artículo que le interesaba y podía buscarlo. Pero ya te digo, era todo a pulmón.
35. Juan Carlos junto con su hermano concurrieron el 20 de junio de 1973 a Ezeiza con motivo del retorno del General Perón (Luis Osvaldo Tedesco, comunicación personal, 20 de septiembre de 2017). 


\section{Q Referencias bibliográficas}

»Tedesco, J. C. (1972). Universidad y clases sociales: el caso argentino. En Revista Latinoamericana de Ciencia Política, núm. 3, pp. 197-227.

»___. (1973). Ideología y Educación. En Los Libros, núm. 31, pp. 4-13.

»__. (1974). Educación y política en América Latina. En Los Libros, núm. 40, pp. 11-16.

»Vasconi, T. (1973). Contra la escuela, borradores para una crítica marxista de la educación. En Revista de Ciencias de la Educación, núm. 9, pp. 3-22.

\section{Bibliografía}

»Amar, H. (2016). Bourdieu en el campo educativo argentino, 1971-1989. Buenos Aires, Biblos.

»Coggiola, O. (2006). Historia del troskismo en Argentina y América Latina. Buenos Aires, Razón y Revolución.

"Jannello, K. (2013). El Boom latinoamericano y la Guerra Fría cultural. Nuevas aportaciones a la gestación de la revista Mundo Nuevo. En Revista Ipotesi, núm. 17, pp.115-133.

» Ruiz Galbete, M. (2013). Los trabajos intelectuales del anticomunismo: el congreso por la libertad de la cultura en América latina. En Nuevo Mundo Mundos Nuevos. Questions du temps présent. En línea: <http://nuevomundo. revues.org/66101> doi: 10.4000/nuevomundo.66101. (Consulta: 00-00-2000).

»Tedesco, J. C. (1970). Educación y sociedad en la Argentina (1880-1900). Buenos Aires, Pannedille.

» . (2005). Educación popular hoy: ideas para superar la crisis. Buenos Aires, Capital Intelectual.

»Tedesco, L. (2006). Lomas del Mirador. Diccionario temático de voces. Buenos Aires, Lozada.

"Tortti, M. (2009), El "viejo" partido socialista y los orígenes de la "nueva" izquierda". Buenos Aires: Prometeo.

» Tortti, M. C. y Blanco, M. C. (2000). El partido socialista argentino y el triunfo de Alfredo Palacios en las elecciones del 5 de febrero de 1961. En Sociohistórica, núm. 7, pp. 281-286.

\section{Breve currículum del autor}

\section{Sebastián Gómez}

Doctor de la Universidad de Buenos Aires en Educación (UBA). Magister de la UBA en Pedagogías Críticas y Problemáticas Socioeducativas. Licenciado en Ciencias de la Educación, UBA. Docente del Departamento de Ciencias de la Educación, UBA. Investigador asistente del Consejo Nacional de Investigaciones Científicas y Técnicas (CONICET). Lugar de trabajo, Instituto de Investigaciones en Ciencias de la Educación (IICE), Facultad de Filosofía y Letras, UBA. Correo electrónico: sebastianjorgegomez@ gmail.com 